\title{
T-CELL RECEPTOR EXPRESSION IN C57BL/6 MICE THAT REJECT OR ARE RENDERED TOLERANT TO BM1 CARDIAC GRAFTS
}

Muhammad Mohiuddin, MD

Vincent Ruggiero, MD

Zhenya Shen, MD

Verdi J. DiSesa, MD
To study the molecular immunologic features of allograft rejection and tolerance induction by intrathymic pretreatment we developed a murine model of cardiac transplantation. In this model the transplant recipient was the C57BL/6 mouse with its major histocompatibility phenotype $\mathbf{H}-2^{b}$. Donors of cells for intrathymic pretreatment and of hearts for grafting were mice of the $b m 1$ mutation. The $b m 1$ mutation involves substitution of three amino acids in one of the alpha helixes of the class $I \mathbf{H}-2 \mathrm{~K}^{\mathrm{b}}$ molecule. Because of the discrete molecular configuration of the transplant antigen we hypothesized that there would be limited heterogeneity of receptor expression on $\mathrm{C} 57 \mathrm{BL} / 6 \mathrm{~T}$ cells responding to $\mathrm{bm} 1$ cardiac grafts and that intrathymic pretreatment would alter the T-cell repertoire of graft recipients by causing elimination of $T$ cells responsible for graft rejection. Mice were given $0.3 \mathrm{ml}$ of antilymphocyte serum intraperitoneally and had intrathymic injection of $25 \times 10^{6} \mathrm{bm} 1$ splenocytes 12 to 21 days before transplantation with a $b m l$ cardiac graft. Flow cytometric analysis of lymph node and spleen cells was used to study the $\mathrm{V}$ beta $\mathrm{T}$-cell repertoire of graft recipients. Cells were stained with monoclonal antibodies to $\mathrm{CD3}$ and $13 \mathrm{~V}$ beta regions $(n=5$, each group) of $T$ cells in naive, sensitized, and tolerant animals. Untreated C57BL/6 mice $(n=9)$ rejected $b m I$ cardiac grafts a mean of 20.4 days after transplantation. Twelve mice pretreated with antilymphocyte serum and intrathymic $b m 1$ cells had permanent graft survival $(>100$ days, $p<0.0001$ ). Animals treated with antilymphocyte serum alone $(n=5)$ or pretreated animals undergoing third-party BALB/c grafts $(n=4)$ rejected grafts in the normal time frame. There was significant alteration of percentage receptor expression of $\mathrm{V}$ beta 5.1, 7, 12, 13, and 17a in sensitized and tolerant mice. Of interest, $\mathrm{V}$ beta 7 expression was increased in the sensitized mice $(3.8 \%$ to $8.3 \%, p=0.005)$ and was virtually eliminated in tolerant mice $(p=0.005)$. In conclusion, these data suggest that $\mathrm{V}$ beta 7 is a critical receptor in the $\mathrm{C57 \textrm {BL } / 6}$ response to subcutaneous $b m I$ cardiac grafts. Pretreatment of graft recipients with one dose of antilymphocyte serum and intrathymic $b m I$ cells appears to produce permanent tolerance to $\mathrm{bml}$ grafts with elimination of $T$ cells expressing receptor chain V beta 7. (J Thorac Cardiovasc Surg 1996;112:310-3)
0 rgan transplantation remains effective therapy for patients with end-stage organ dysfunction but results remain limited by the imperfections and

From the Department of Surgery, Medical College of Pennsylvania, Philadelphia, Pa.

Received for publication May 12, 1995; revisions requested August 17, 1995; revisions received Nov. 27, 1995; accepted for publication Dec. 5, 1995.

Address for reprints: Verdi J. DiSesa, MD, Cardiothoracic Surgery, The Medical College of Pennsylvania, 3300 Henry Ave., Philadelphia, PA 19129.

Copyright 11996 by Mosby-Year Book, Inc.

$0022-5223 / 96 \$ 5.00+0 \quad \mathbf{1 2} / \mathbf{1 / 7 1 0 1 2}$ side effects of immunosuppressive therapy. Improved understanding of the rejection response and biologic methods to produce specific tolerance to grafted tissues will improve the results of organ transplantation. This is the age of molecular medicine. Understanding of the molecular immunologic basis of graft rejection and tissue-specific methods to prevent it will be required to produce fundamental new advances in organ transplantation.

We have developed an animal model of organ transplantation that allows studies of the processes of rejection and induction of tolerance at a molecular level. ${ }^{1}$ We have used strains of mice as donor 
$(b m l)$ and recipient of grafted tissue (C57BL/6) that differ only by substitution of three amino acids on one class I major histocompatibility complex (MHC) molecule. ${ }^{2}$ The $b m l$ mutation contains a three-amino-acid substitution on one alpha helix of the $\mathrm{H}-2 \mathrm{~K}^{\mathrm{b}} \mathrm{MHC}$ molecule. This difference is sufficient to cause rejection of a subcutaneous cardiac graft an average of 20 days after transplantation. Our work and that of other laboratories have shown that intrathymic pretreatment of graft recipients with donor-specific cells produces allograft tolerance in a rat model of cardiac transplantation. ${ }^{3-8} \mathrm{We}$ sought to reproduce and study this result in our murine model.

Because the three-amino-acid difference between donor and recipient tissues produces a discrete molecular antigenic configuration, we hypothesized that a limited repertoire of T-cell receptors would be expressed on recipient $\mathrm{C} 57 \mathrm{BL} / 6$ cells, causing rejection of $b m 1$ grafts. If this were the case we reasoned that our model system would allow investigation of the hypothesis that intrathymic pretreatment causes deletion of recipient $T$ cells expressing this receptor chain. We believed that a deletion mechanism was plausible because this process appears to be crucial in normal immune ontogeny.

The present studies were designed to characterize the rejection response to subcutaneous cardiac grafts in our model system and to demonstrate induction of tolerance with the intrathymic pretreatment strategy. Furthermore, we sought to examine the $\mathrm{T}$-cell receptor repertoire on naive recipient mice, those rendered sensitized to donor tissue by rejection of a previous graft, and those rendered tolerant to donor tissue by intrathymic pretreatment. We believe that this model system and the results of our studies help us begin to develop a molecular understanding of these important events in organ transplantation.

\section{Material and methods}

Animals. Eight-week-old male C57BL/6 mice were used as the recipients of heart and intrathymic spleen cells. Male $b m l$ mice of the same age were used as donors of heart and spleen cells. All animals were purchased from Jackson Laboratory and were housed in a virus-free facility. The C57BL/6 mouse is MHC phenotype $\mathrm{H}-2^{\mathrm{b}}$. The $b m I$ mutation differs only by substitution of three amino acids in one of the alpha helixes of the $\mathrm{H}-2 \mathrm{~K}^{\mathrm{b}}$ molecule. ${ }^{1}$

All animals were cared for in compliance with the "Principles of Laboratory Animal Care" formulated by the National Society for Medical Research and the "Guide for the Care and Use of Laboratory Animals" prepared by the Institute of Laboratory Animal Resources and published by the National Institutes of Health (NIH Publication No. 86-23, revised 1985).

Cardiac transplantation technique. We used the technique of split ear cardiac grafting. ${ }^{9}$ A pouch was made in the pinna of the C57BL/6 recipient mouse ear and a whole neonatal ( 24 to 48 hours old) heart from a $b m 1$ donor was placed in it. This is not an immediately vascularized graft. Although operative time is short ( $<1$ hour) graft contractions uniformly do not start for 5 days. Graft survival as determined by the presence of ventricular pulsatile activity was checked every day by visual inspection with a $\times 20$ dissecting microscope. Cessation of heartbeat after initial pulsatile activity was considered to be caused by rejection, which was confirmed histologically. All rejected grafts had infiltration by small lymphocytes and myocyte destruction seen on hematoxylin and eosin staining of tissue sections examined by light microscopy. Control isogenic grafts beat indefinitely once contractions start and are histologically normal on pathologic examination.

Tolerance induction. Whole spleen was disrupted by passage through a wire mesh. Red blood cells were lysed with Tris $\mathrm{NH}_{4} \mathrm{Cl}$. Cells were washed with RPMI 1640 medium and were injected intrathymically under direct vision at a concentration of $25 \times 10^{6}$ cells in $0.5 \mathrm{ml}$ of the medium. Cells were injected 1 day after intraperitoneal injection of $0.3 \mathrm{ml}$ murine antilymphocyte serum (ALS) purchased from Intercell Technologies (Hopewell, N.J.). Heart transplantation was done 12 to 21 days later.

Flow cytometry. Cells for flow cytometric study were obtained from spleen and lymph nodes of the animal to be tested and were prepared in the same manner already described. Two-color analysis was done. Simultaneous staining was done with phycoerythrin-labeled anti-CD3 antibody for the identification of $\mathrm{T}$ cells and fluorescein isothiocyanate-labeled antibodies for the identification of the different $\mathrm{V}$ beta receptors. Cells were counted with use of a Becton Dickinson fluorescence-activated cell sorter. The T-cell receptor regions evaluated were $\mathrm{V}$ beta 2, 3, 5.1/5.2, 6, 7, 8.1/8.2, 9, 10,11, 12, 13,14, and 17a. All antibodies were purchased from Pharmingen (San Diego, Calif.). The percentages of cells that stained positive for both CD3 and each V beta region were calculated. Cells from naive, sensitized, and tolerant animals were studied. Sensitized animals underwent cardiac grafting without pretreatment. Analysis was done on about day 25 when the rejection process was established. Cells from tolerant animals were studied after 100 days with a beating heart graft.

\section{Results}

Results of intrathymic manipulation are shown in Table I. The mean survival time of the heart grafts in the untreated group was 20.4 days. ALS alone did not prolong graft survival significantly. Mice treated with ALS and intrathymic splenocytes had indefinite heart graft survival ( $>100$ days). Third-party $\mathrm{BALB} / \mathrm{c}$ grafts placed in treated animals were rejected normally.

Flow cytometry results are shown in Table II. Five 
Table I. Effect of intrathymic manipulation on graft survival

\begin{tabular}{|c|c|c|c|}
\hline Groups & $n$ & $\begin{array}{l}M S T \pm S D \\
\quad \text { (days) }\end{array}$ & $\begin{array}{l}L S T \\
\text { (days) }\end{array}$ \\
\hline Naive & 9 & $20.4 \pm 11.0$ & 49 \\
\hline ALS & 5 & $25.8 \pm 9.3$ & 38 \\
\hline $\begin{array}{l}\text { ALS and intrathymic } \\
\text { injection }\end{array}$ & 12 & $>100.0 \pm 0.0^{*}$ & $>100$ \\
\hline Third party & 4 & $11.8 \pm 1.3$ & 13 \\
\hline
\end{tabular}

$M S T$, Mean survival time; $S D$, standard deviation; $L S T$, longest survival time.

${ }^{*} p<0.0001$.

$\mathrm{V}$ beta receptor regions showed significant changes in percent expression in sensitized animals and in animals made tolerant by intrathymic pretreatment. Of note, the percentage of $\mathrm{T}$ cells bearing the $\mathrm{V}$ beta 7 region was increased from $3.77 \%$ to $8.3 \%$ in sensitized mice. Expression of $\mathrm{V}$ beta 7 was virtually eliminated in tolerant mice.

\section{Discussion}

This study demonstrates the feasibility of using our mouse model of organ transplantation for the molecular study of important events in transplant rejection and acquired tolerance. We are convinced that understanding at the level of the molecules is important in advancing our understanding of these important processes and in advancing therapy for organ transplant recipients. The solution of the crystal structure of the $\mathrm{MHC}$ molecule ${ }^{10,11}$ provided opportunities for explosive growth in the understanding of fundamental immune processes. Similar explosive growth is possible in transplantation science if we can develop molecular immunologic bases for understanding graft rejection and its control.

Our work supports our hypothesis that a molecularly discrete transplantation antigen elicits a T-cell immune response that is marked by limited heterogeneity of T-cell receptor expression. We have observed apparent critical importance of the T-cell receptor $\beta$ chain variable segment $V$ beta 7 in the rejection response of a $\mathrm{C} 57 \mathrm{BL} / 6$ mouse to a $b m 1$ heart graft. Limited heterogeneity of receptor expression has been observed in other immune systems in which the response is to an antigen of discrete molecular structure. Similar observations have been made in models of allergic encephalitis ${ }^{12,13}$ and arthritis $^{14}$ and in the physiologic immune response to the Mls antigen. ${ }^{15}$ This makes intuitive sense because the purpose of T-cell receptor fine specificity is the distinction of subtle molecular differences.
Table II. Percentage V beta region T-cell receptor expression

\begin{tabular}{lcccc}
\hline V beta & $n$ & Naive & Sensitized & Tolerant \\
\hline 2 & 5 & $6.90 \pm 0.34$ & $6.80 \pm 1.80$ & $7.19 \pm 1.71$ \\
3 & 5 & $3.49 \pm 0.76$ & $3.43 \pm 0.31$ & $3.37 \pm 0.43$ \\
5.1 & 5 & $1.24 \pm 0.60$ & $3.87 \pm 1.05^{*}$ & $7.70 \pm 0.59^{*} \dagger$ \\
6 & 5 & $7.59 \pm 1.33$ & $10.13 \pm 2.89$ & $12.10 \pm 1.74^{*}$ \\
7 & 5 & $3.77 \pm 2.00$ & $8.29 \pm 0.71^{*}$ & $0.43 \pm 0.14^{*} \dagger$ \\
$8.1,8.2$ & 5 & $18.79 \pm 1.21$ & $17.46 \pm 1.35$ & $20.08 \pm 0.5 \dagger^{\dagger}$ \\
9 & 5 & $3.25 \pm 0.66$ & $4.26 \pm 1.42$ & $5.77 \pm 2.28$ \\
10 & 5 & $5.12 \pm 0.79$ & $5.09 \pm 0.54$ & $8.52 \pm 3.14$ \\
11 & 5 & $5.41 \pm 0.15$ & $4.68 \pm 0.21$ & $5.56 \pm 0.70$ \\
12 & 5 & $5.77 \pm 0.53$ & $7.56 \pm 0.50^{*}$ & $10.47 \pm 2.18^{*} \dagger$ \\
13 & 5 & $3.30 \pm 0.62$ & $1.08 \pm 0.20^{*}$ & $1.68 \pm 0.45^{*}$ \\
14 & 5 & $5.43 \pm 1.21$ & $6.17 \pm 0.41$ & $5.95 \pm 0.79$ \\
$17 \mathrm{a}$ & 5 & $3.15 \pm 1.12$ & $5.76 \pm 0.41^{*}$ & $4.49 \pm 0.62$ \\
\hline
\end{tabular}

${ }^{*} p=0.005$ (naive versus sensitized/tolerant).

$\grave{\dagger} p=0.005$ (sensitized versus tolerant).

Our data also begin to provide insight into the mechanism by which pretransplant intrathymic manipulations produce acquired tolerance to allogeneic tissues. Since the initial description of the efficacy of intrathymic pretreatment with alloantigen, ${ }^{6}$ investigators have speculated that this treatment strategy produces acquired tolerance by altering the immune-cell repertoire. In an analogy to normal immune ontogeny, ${ }^{16-18}$ placement of allogeneic cells in the thymus is thought to lead to the deletion of $T$ lymphocytes that ordinarily respond to these alloantigens. The theory is that the single dose of antilymphocyte serum depletes the body of mature lymphocytes including those that would respond to an allograft. When the lymphocyte population is reconstituted with new $T$ cells that mature in the thymus after introduction of alloantigen the altered thymic milieu leads to deletion of alloreactive cells. Our data showing elimination of $\mathrm{V}$ beta 7 receptor expression in tolerant animals is evidence in favor of a deletion mechanism as an important component of tolerance in this system.

We have not in this model investigated other potential mechanisms of tolerance induction including the development of immune anergy or a distinct population of suppressor cells. In separate experiments in a rat model we have shown a transferable cell population that leads to prolonged allograft survival although permanent tolerance has not been achieved (unpublished data). It is possible that intrathymic pretreatment produces a variety of mechanisms whereby permanent allograft survival is achieved. Understanding of this phenomenon requires future study. 
Other investigation is also required to develop a complete understanding of our present observations. It would be desirable to analyze receptor expression on the lymphocytes that actually invade heart grafts. We hypothesize that the $\mathrm{V}$ beta 7 receptor chain would predominate on lymphocytes harvested from rejected grafts. Other planned investigations include studying the effects of monoclonal antibodies to specific receptor chains in the in vivo transplant model and in vitro assays such as the mixed lymphocyte reaction. We plan to extend our study to other $b m$ mutations, which offer the opportunity to study the differential response to other alterations in the molecular configuration of $\mathrm{H}-2 \mathrm{~K}^{\mathrm{b}}$. For instance, $b m 23$ has substitutions in a different portion of the opposite alpha helix of the class I molecule and might be expected to elicit a response from a different population of $\mathrm{T}$ cells expressing a different receptor chain.

Finally, we need to modify our pretreatment protocols such that this strategy might be applicable to clinical transplant situations. One logical set of experiments would be to compress the pretreatment interval to several hours before transplantation. For instance, antilymphocyte serum could be given 3 to 6 hours before intrathymic inoculation with allogeneic cells and performance of the tissue allograft. It is easy to envision how this protocol might be applied clinically and therefore it is important to determine whether such treatment produces significant prolongation of graft survival. If so, appropriate clinical trials might be indicated.

We are committed to the concept that the control of allograft rejection in a nontoxic and specific fashion requires a molecular immunologic understanding of the important events in rejection. We believe that our preliminary work establishes the potential efficacy of our mouse model for studying these processes at the molecular level. Furthermore, our data suggest that the intrathymic pretreatment strategy can be studied productively at a fundamental level and may produce insights that will be useful in clinical organ transplantation.

\section{REFERENCES}

1. DiSesa VJ. Molecular immunology of the allograft rejection: insight from MHC mutants and crystal structure. J Heart Lung Transplant 1991;10:111-6.
2. Nathenson SG, Geliebter J, Pfaffenbach GM, et al. Murine major histocompatibility complex class I mutants: molecular analysis and structure function implications. Annu Rev Immunol 1986;4:471-502.

3. Kline GM, Shen Z, Mohiuddin M, et al. Successful experimental heart transplantation without immunosuppressive drugs. J Heart Lung Transplant 1993;12:388-93.

4. Shen Z, Kline GM, Mohiuddin M, DiSesa VJ. Histocompatibility differences and cardiac transplant tolerance produced by intrathymic pretreatment. J Thorac Cardiovasc Surg 1994; 107:1472-5.

5. Shen Z, Mohiuddin M, DiSesa VJ. Durability of donorspecific and organ-specific heart transplant tolerance induced by intrathymic pretreatment with allogeneic spleen cells. Surg Forum 1994;45:237-9.

6. Posselt AM, Campos L, Mayo GL, et al. Selective modulation of T-cell immunity by intrathymic cellular transplantation. Transplant Rev 1993;7:200-13.

7. Odorico JS, Posselt AM, Naji A, et al. Promotion of rat cardiac allograft survival by intrathymic inoculation of donor splenocytes. Transplantation 1993;55:1104-7.

8. Goss JA, Nakafusa Y, Yu S, Flye MW. Intrathymic injection of donor alloantigens induces specific tolerance to cardiac allografts. Transplantation 1993;56:166-73.

9. Fulmer RI, Cramer AT, Libelt RA, et al. Transplantation of the cardiac tissue in the mouse ear. Am J Anat 1963;118:273.

10. Bjorkman PJ, Saper MA, Samraoui B, Bennett WS, Strominger JL, Wiley DC. Structure of the human class 1 histocompatibility antigen, HLA-A2. Nature 1987;329:506-12.

11. Bjorkman PJ, Saper MA, Samraoui B, Bennett WS, Strominger JL, Wiley DC. The foreign antigen binding site and $\mathrm{T}$ cell recognition regions of class I histocompatibility antigens. Nature 1987;329:512-8.

12. Kuchroo VK, Sobel RA, Laning JC, et al. Experimental allergic encephalomyelitis mediated by cloned $T$ cells specific for a synthetic peptide of myelin proteolipid protein: fine specificity and $\mathrm{T}$ cell receptor $\mathrm{V}$ beta usage. $\mathrm{J}$ Immunol 1992;148:3776-82.

13. Kotzin BL, Karuturi S, Chou YK, et al. Preferential T-cell receptor beta chain variable gene use in myelin basic proteinreactive T-cell clones from patients with multiple sclerosis. Proc Natl Acad Sci U S A 1991;88:9161-5.

14. Haqqi TM, Anderson GD, Banerjee S, et al. Restricted heterogeneity in T-cell antigen receptor $V$ beta gene usage in the lymph nodes and arthritic joints of mice. Proc Natl Acad Sci U S A 1992;89:1253-5.

15. MacDonald HR, Schneider R, Lees RK, et al. T-cell receptor $\mathrm{V}$ beta use predicts reactivity and tolerance to $\mathrm{Mls}^{\mathrm{a}}$-encoded antigens. Nature 1988;332:40-5.

16. Kronenberg M. Self-tolerance and autoimmunity. Cell 1991; 65:537-42.

17. Blackman M, Kappler J, Marrack P. The role of the T cell receptor in positive and negative selection of developing $\mathrm{T}$ cells. Science 1990;248:1335-41.

18. Schwartz RH. Acquisition of immunologic self-tolerance. Cell 1989;57:1073-81. 